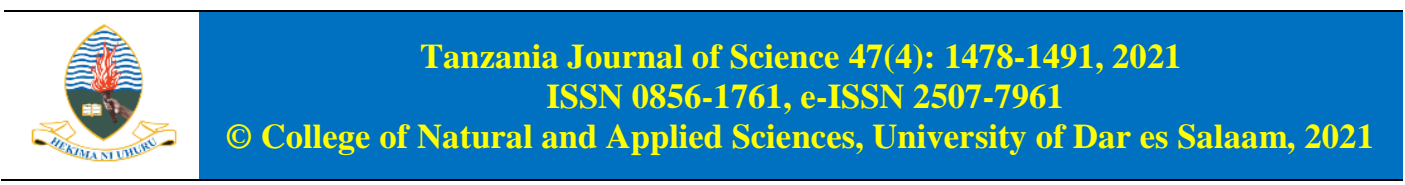

\title{
Impacts of Wood Fuel Uses on Forest Cover: The Case of Semiarid Areas in Northern Tanzania
}

\author{
*Debora J Mahushi", Revocatus L Machunda ${ }^{2}$ and Talam E Kibona ${ }^{1}$ \\ ${ }^{1}$ Department of Mathematics, Physics and Informatics, Mkwawa University College of Education, \\ University of Dar es Salaam, P.O. Box 2513, Iringa, Tanzania \\ ${ }^{2}$ Department of Water and Environmental Science and Engineering, Nelson Mandela African \\ Institution of Science and Technology, P.O. Box 447 Arusha, Tanzania \\ *Corresponding author email: mahushid@yahoo.com
}

Received 21 Jun 2021, Revised 22 Oct 2021, Accepted 25 Oct 2021, Published Oct 2021

DOI: https://dx.doi.org/10.4314/tjs.v47i4.13

\begin{abstract}
Satellite images for the years 1987, 1997, 2002 and 2017, and questionnaire surveys were used to assess energy sources and demands as well as the impacts of wood fuel use to forest cover changes in Meru and Mwanga Districts. The major energy sources identified include cow dung cake, firewood, charcoal, liquefied petroleum gas and biogas. The total energy demands from these sources were 1400 (in Meru), 6289, 724 and $21 \mathrm{~kg}$ per day, respectively. The amount of biogas was not quantified since the reactors were constructed locally with no reading meter. Analysis from Landsat images showed variations in forest cover. The areas covered with forests in Meru were found to be 1510, 1723, 1612 and 1327 ha for 1987, 1997, 2002 and 2017, respectively. The changes observed in Mwanga District were 31705, 31988, 17939 and 30960 ha for 1987, 1997, 2002 and 2017, respectively. From the findings it was observed that, the ongoing use of wood fuel in semi-arid areas of Meru and Mwanga could deplete forests completely. The study concludes that charcoal and firewood consumptions are real threats to the long-term persistence of forests in Tanzania and proposes the use of renewable energy such as biogas for alleviating forest losses.
\end{abstract}

Keywords: Biogas, energy sources, Satellite images.

\section{Introduction}

Forests are important sources of livelihoods to millions of people globally and contribute to national economic development of many countries (Sunderlin et al. 2005). Forests provide wood fuels as the primary sources of energy, which occasionally meets as much as $90 \%$ of energy requirements in developing countries (Trossero 2002). Forests and wood resources in Tanzania which cover about 48 million hectares (Ministry of Natural Resources and Tourism 2014) provide various goods and services including energy, construction materials and medicines. The country is facing extraordinary loss of its forests up to present.
Between 1990 and 2010, it lost an average of 403350 ha per year which were estimated to be $19.4 \%$ (about $8067000 \mathrm{ha}$ ) of the forest cover within a period of twenty (20) years (Miya et al. 2012). Recent reports indicate that the country had already lost about $38 \%$ of its forest cover, and if no measures are taken, the entire forests in Tanzania will be pooped within the next 50 to 80 years (Luoga et al. 2000). Through the periods of 1980-1995 and 19952010, the forest reserves in Tanzania have shown a substantial degradation mainly due to charcoal making, logging, shifting agriculture, firewood, pole cutting, expansion of commercial farms and climate changes (Chiesa 1478 
et al. 2009). Forest degradation in Tanzania has been identified as a function of social, economic and governance factors such as human population growth, political instability of neighbouring countries, poverty, urbanization, trade, expansion of agricultural lands, developing of new economic paths and infrastructure development (Miya et al. 2012). Studies conducted in 1980s and 1990s reported strong relationships between population growth and deforestation in Central America, Africa, and South Asia (Rudel et al. 2000). It is clearly linked with population growth if and only if the growing community depends much on forest products such as fuelwood, building materials, other goods and services (Miya et al. 2012). Consumption and demands are very important factors for understanding the impacts of wood fuel use on forest cover; however, it has always been hampered by lack of reliable information (Arnold and Persson 2003). Various studies rarely report that the greater part of consumption in rural areas is by poor households, and therefore it has been difficult to determine the magnitude of wood fuel use and its impacts on forests and rural livelihoods (Arnold and Persson 2003). The consumption of wood fuel in rural areas includes all dwellers; however, limited studies have been carried out in pastoralist communities to find out the levels of forests degradation (Specht et al. 2015). The valuations of the actual amounts of wood fuel usage and the influences on forests and rural livelihoods have subsequently been difficult to determine and has remained the subject of significant discussion (Mwampamba et al. 2013). Sawe (2004) reported that, wood fuels are the most widely used sources of domestic energy in Tanzania and are among the most significant causes of forest degradation in many developing countries (Luoga et al. 2000).
Statistically the cleared forest areas in semiarid areas where Maasai communities reside are not well known (Arnold and Persson 2003). Maasai communities previously were depending on milk and fresh meat as their main foods, but due to climate changes, pastures for the cattle have been reduced allowing these communities to change their life styles. Changing of climatic conditions requires these communities to adopt new adaptation strategies including change of diet (from milk and fresh meat feeding to other types of food that entail more energy during preparation). Maasai pastoralist communities living in arid and semiarid areas, their dependence on fuelwood as the main sources of energy and the uses of trees for fencing contribute much to deforestation (Specht et al. 2015). However, most of the studies in Tanzania have largely been conducted in areas outside the Maasai land. Due to dependence on wood fuel and other activities, forests go on decreasing, converting semi-arid areas into arid areas. In order to identify the rates of forest degradation in some of these areas, Mwanga (Lembeni, Njoro and Mgagao) and Meru (Ngarenanyuki and Oldonyosambu) (Figure 1) which are semi-arid areas in northern Tanzania were selected as study areas. Energy sources used, fuelwood consumption, demands and satellite images classification were carried out in order to come up with the impacts of wood fuel uses on forest degradation.

\section{Materials and Methods \\ Study area description}

The study was conducted at Lembeni, Njoro and Mgagao in Mwanga District (Kilimanjaro Region), Oldonyosambu and Ngarenanyuki of Meru District in Arusha region which are both semi-arid areas with approximately same climatic conditions (Figure 1). 


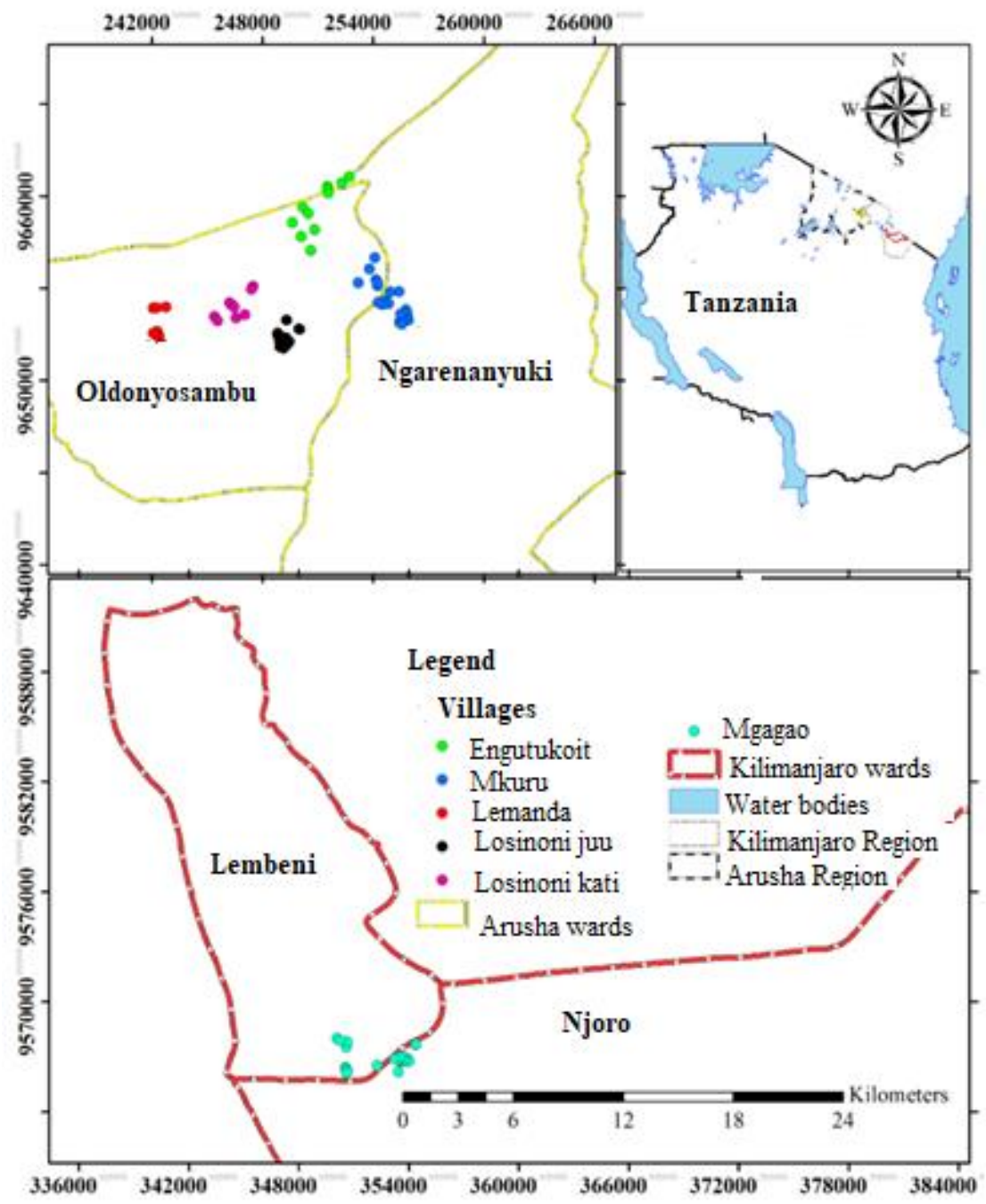

Figure 1: A map showing the study areas.

\section{Analysis of exisisting energy sources and their demands}

In order to understand the existing energy sources (firewood, charcoal, biogas, cow dung cake and liquefied petroleum gas) and their demands, questionnaires were administered. Wood fuel demand quantification was done by weighing the amounts of charcoal and firewood used per day for each family surveyed. Before conducting the questionnaire survey, sample size to be used was determined by using Equation 1 at the precision rate $(e)$ of 7 and 93\% confidence level for Meru and Mwanga (Dell et al. 2002). The sample size obtained using Equation 1 was 207 for the population with 5281 households in Meru and 100 for the population with 1278 households in Mwanga. The types of interviews conducted were both structured and unstructured interviews. Oral interview was used to interviewees who had no 
ability of reading and writing. The Statistical Product and Service Solutions (SPSS) software was used in analyzing the data collected from the interviews. Data were firewood analyzed in frequencies and percentages after coding and were presented in charts (Figures 3 and 4). Unique identifiers to each individual data were used and the text responses were coded in numerical forms for easy analysis (example: 1 to reflect firewood users, 2 to reflect charcoal users, 3 to reflect liquefied petroleum gas users and 4 to reflect cow dung cake users).. Through interviews (questionnaire surveys), energy sources existing in the study sites were determined. The average domestic demands of charcoal, dry cow dung cake and liquefied petroleum gas used in cooking were identified.

$$
\boldsymbol{n}=\frac{\mathbf{N}}{1+\mathrm{N}(e)^{2}} ;
$$

where $e=$ precision rate, $n=$ Sample size, $\mathrm{N}$ $=$ Total population

\section{Effects of firewood and charcoal use on forest cover \\ Remote sensing data}

Three-time series pairs of Landsat (TM and OLI) images for the years 1987, 1997, 2002 and 2017 (Figures 5 and 6) covering the study areas were utilized as the principal sources of data. In order to avoid differences in vegetation phenology, the used images were captured on the same day or season (dry periods of JanuaryFebruary and July-August) of the year, collected under relatively clear sky conditions.

\section{Image pre-processing and processing}

Images were radiometrically and geometrically calibrated and registered to the Universal Transverse Mercator (UTM) map coordinate system (i.e. UTM Zone 36 and 37 South, Spheroid Clarke 1880, Datum WGS 1984). Distinct features on the image (e.g. roads intersections, hills and other features) were used to establish Ground Control Points (GCP) for geometric calibration in order to match their corresponding coordinates on the ground. Atmospheric corrections were applied to correct the images for atmospheric scattering such as haze. Both radiometric and atmospheric corrections were achieved through use of the Atmospheric Correction Tool in PCI. Imageries were then clipped to a boundary of study wards before classification, with a purpose of quick processing and better collection of sample points.

Stratified-random sampling technique following methods described in Foody (2002) was employed in acquiring training and validation samples for land use/cover classification in the study areas. Fifty sample points per land use/cover class were randomly generated over the study area (Congalton 1991, Lillesand et al. 2014). The method was chosen because it reduces biases in collection of sample points, ensures that all classes are adequately represented, and an equal chance for samples (Foody 2002). Samples were spaced $500 \mathrm{~m}$ interval to avoid auto-correlation (Rutherford et al. 2007) The collected samples were initially assigned at 8-10 land use/cover classes using high resolution Google Earth imageries. For difficult and/or confusing classes to identify in Google, images were assessed based on expert knowledge of the study areas. Image spectral signatures were visualized in scatter and/or signature plots to evaluate class signature separability using the Bhattacharyya Distance and or Transformed Divergence in PCI. Classes with an index between 1.9 and 2.0 were considered separable. Iterative process of merging and editing signature classes was performed until reasonably high-quality signature separability (for those classes of less than 1.9) achieved per class. The classification accuracy, which is an indication of how well the image classified, was calculated following procedures described by Zhan et al. (2002). The classification error and/or confusion matrix, per each land cover map was also calculated. Image classification was performed using the Maximum Likelihood Classification (MLC) in PCI Geomatica using the approach in Figure 2. 
Mahushi et al. - Impacts of wood fuel uses on forest cover ...

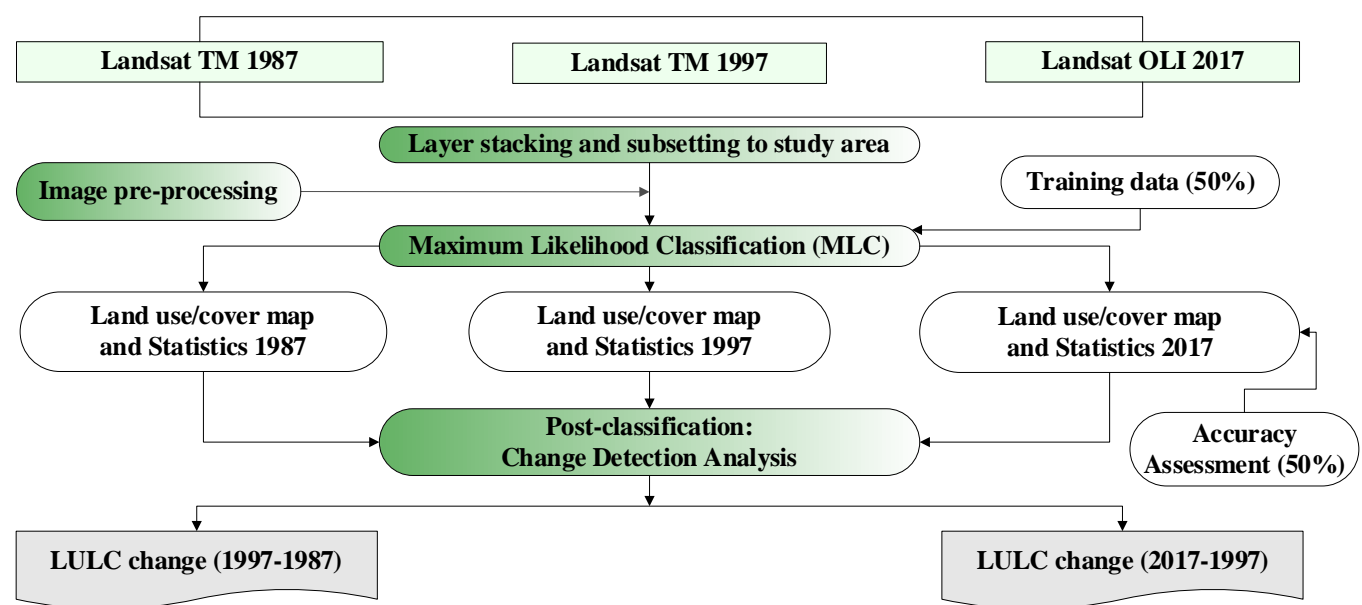

Figure 2: Approach for image classification using the Maximum Likelihood Classification (MLC).

\section{Change detection/post classification analysis}

Post-classification/change detection method is the most widely used technique to ascertains the type, magnitude and spatial aspects of cover and use changes between two temporal images to detect the differences (Mengistu and Salami 2007). In this study, a postclassification comparison among three time series (1987-1997, 1997-2002 and 2002-2017) (Figures 5 and 6) images was performed using Semi-Automatic Classification Plugin in QGIS software (Congedo 2013) to assess the land use changes that occurred between 1987-1997, 1997-2002 and 2002-2017 as shown in Figures 5 and 6.

\section{Results and Discussion \\ Results}

\section{Energy sources and demands}

The existing energy sources identified include liquefied petroleum gas, biogas, charcoal, firewood and dry cow dung cake. The demands for the energy sources recognized are presented in Figure 3. Firewood was named to be the most preferred source of energy than other sources. The 2012 population census conducted in Mwanga (Mgagao, Lembeni and Njoro) and Meru (Ngarenanyuki and Oldonyosambu wards) reported a population size of 31623 people at the average family size of 4.8 which is nearly 6588 households (NBS 2012). For the 6588 households, only 207 and 100 households for Meru and Mwanga, respectively were selected as sample sizes. About $97 \%$ and $95 \%$ (equivalent to 200 and 82) for Meru and Mwanga, respectively were recognized to rely on wood fuels as their main energy sources. These included households that depend on wood fuel completely (130 and 76) and those reported mixed use of wood fuel and other energy sources (70 and 6) for Meru and Mwanga, respectively. The remained number (7 and 18 households) reported to depend on charcoal. See Figure 4.

About $1400 \mathrm{~kg}$ of dry cow dung cake (in Meru), 2093 and $4196 \mathrm{~kg}$ of firewood, 308 and $416 \mathrm{~kg}$ of charcoal for the selected sample sizes in Mwanga and Meru, respectively were found to be consumed per day. With 1278 and 5281 households in Mwanga and Meru, respectively, 107 and 27 tons of firewood, 4 and 11 tons of charcoal and 36 tons of cow dung cake (Meru) are expected to be spent per day. Finding out the energy demands for Mwanga (Lembeni, Njoro and Mgagao) and Meru (Ngarenanyuki and Oldonyosambu wards) per year gives many tons of firewood, charcoal and cow dung cake equivalent to 48838,5312 and 13037 tons, respectively. 


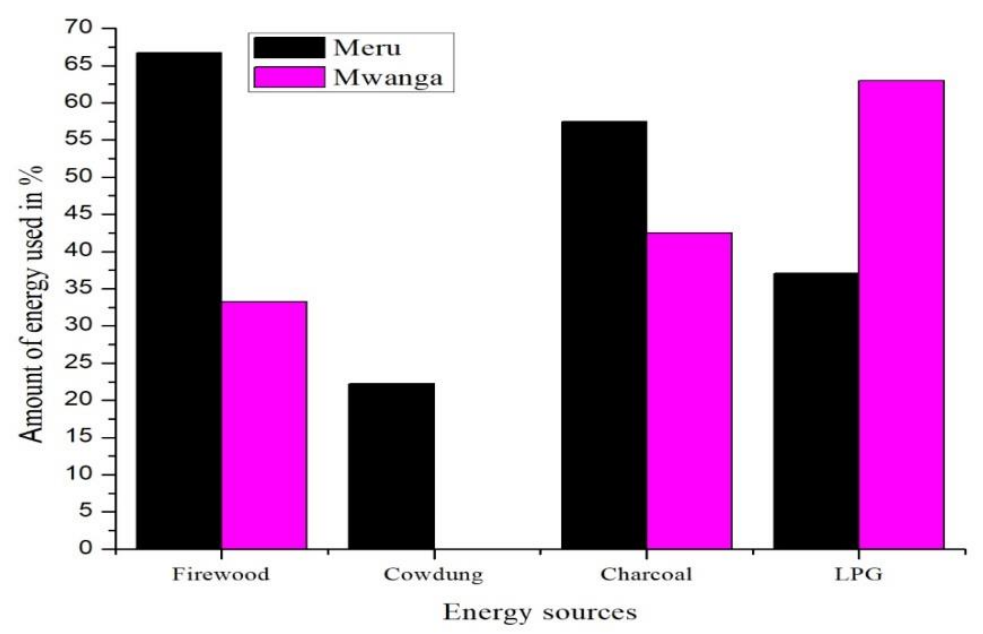

Figure 3: Types and amounts of energy sources used for cooking.

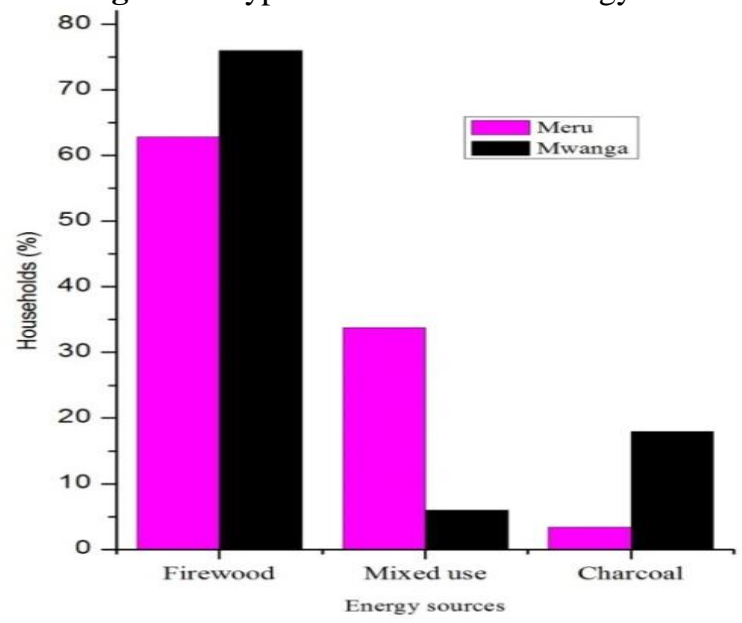

Figure 4: Energy sources that are used in cooking per respective number of households (Mixed use: Firewood, charcoal, dry cow dung, biogas and LPG).

\section{Effects of biomass fuel use on forest cover}

Statistical data from the extracted and classified images showed fluctuations in areas covered by forests (Table 1). An increase of 283 ha of forested area was identified in 1987 to 1997 for Mwanga District, a rapid change was also recognized in 1997 to 2002 where by 14049 ha were lost. In 2002 to 2017, a gradual change was detected compared to the loss observed in 1997-2002 where by 13022 ha increased during this period of time. In Meru District, an increase of 213 ha was identified within a period of 10 years, from 1987 to 1997. This was followed by a decrease of 111 ha for a period of 5 years from 1997 to 2002; a rapid change was once again recognized in 20022017 where by 285 ha were lost. 
Mahushi et al. - Impacts of wood fuel uses on forest cover ...

Table 1: Trends in total (net) forest cover in Meru and Mwanga from 1987 to 2017

\begin{tabular}{|c|c|c|c|c|c|c|c|c|}
\hline Year & $\begin{array}{c}\text { Forest cover } \\
\text { (ha) }\end{array}$ & \multirow{2}{*}{$\begin{array}{c}\text { Forest cover } \\
\text { (ha) Meru }\end{array}$} & \multicolumn{2}{|c|}{ 1987-1997 } & \multicolumn{2}{|c|}{$1997-2002$} & \multicolumn{2}{|c|}{$2002-2017$} \\
\cline { 4 - 9 } & Mwanga & & & & & & & \\
\hline 1987 & 31705 & 1510 & Mwanga & Meru & Mwanga & Meru & Mwanga & Meru \\
\cline { 5 - 10 } 1997 & 31988 & 1723 & & & & & & \\
2002 & 17939 & 1612 & 28.3 & 21.3 & -2809.8 & -22.2 & 868.1 & -19 \\
2017 & 30960 & 1327 & & & & & & \\
\hline
\end{tabular}
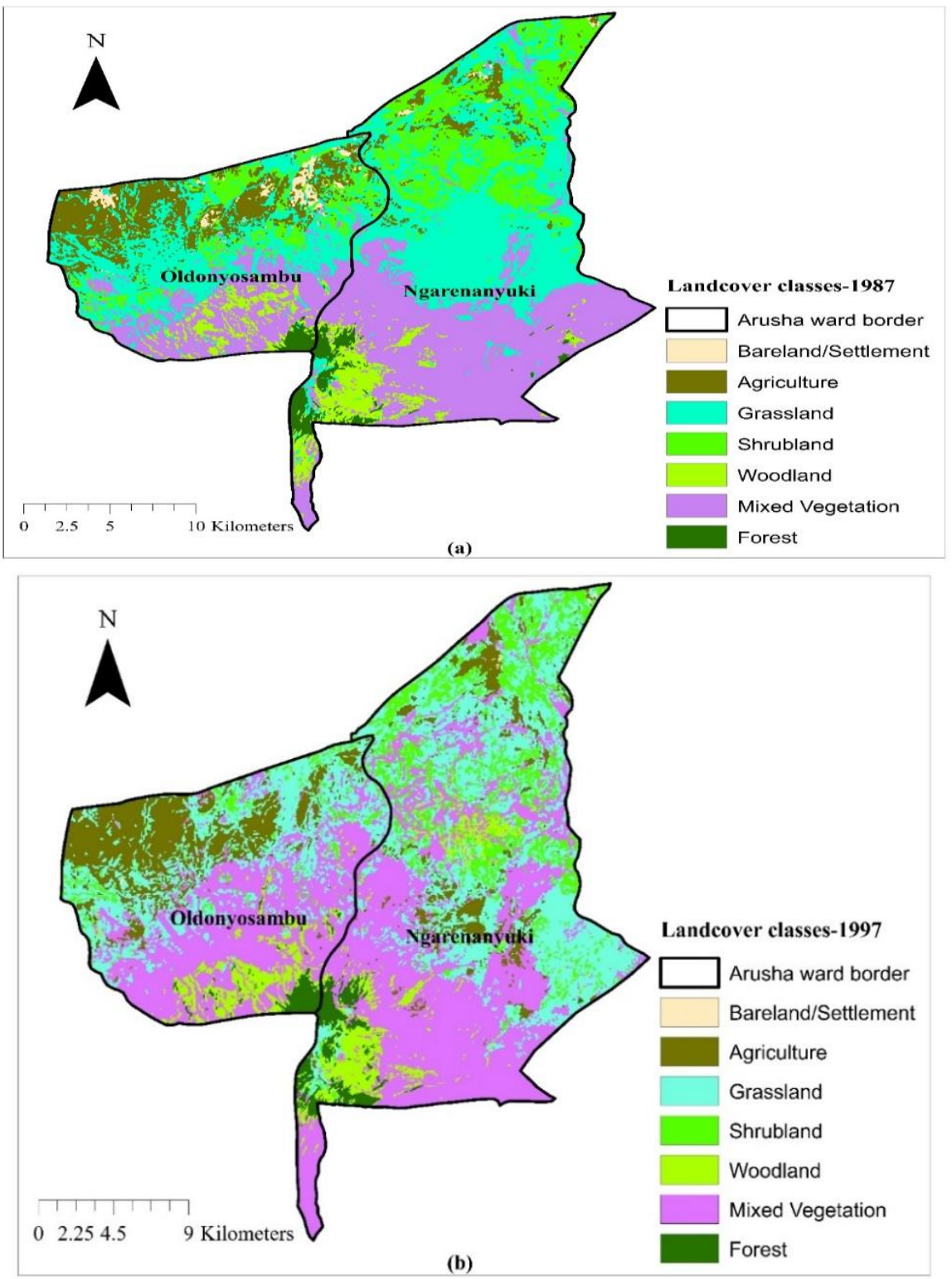

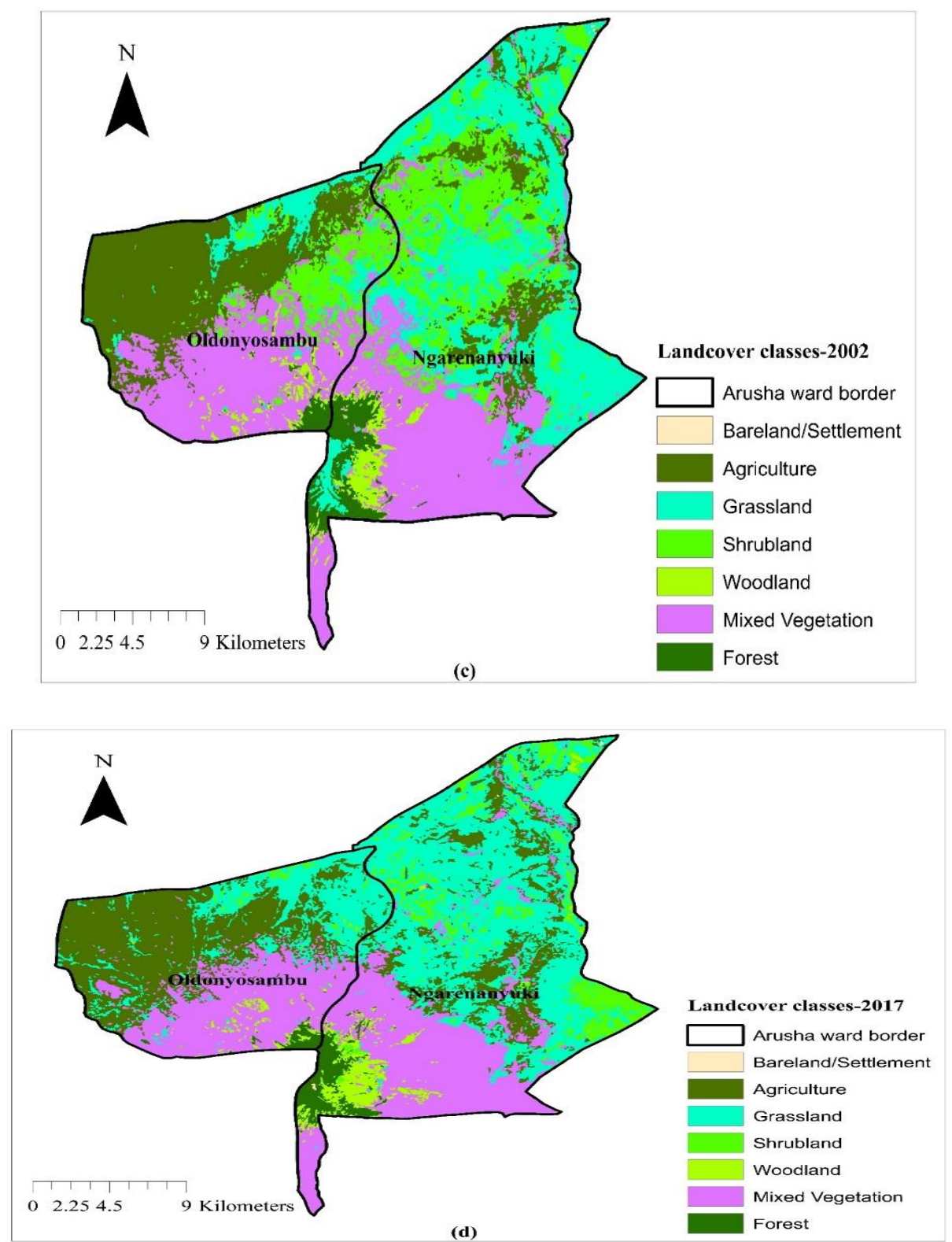

Figure 5: Image classification for (a) 1987 (b) 1997 (c) 2002 and (d) 2017 land cover classes in Meru District (Arusha). 
Mahushi et al. - Impacts of wood fuel uses on forest cover ...
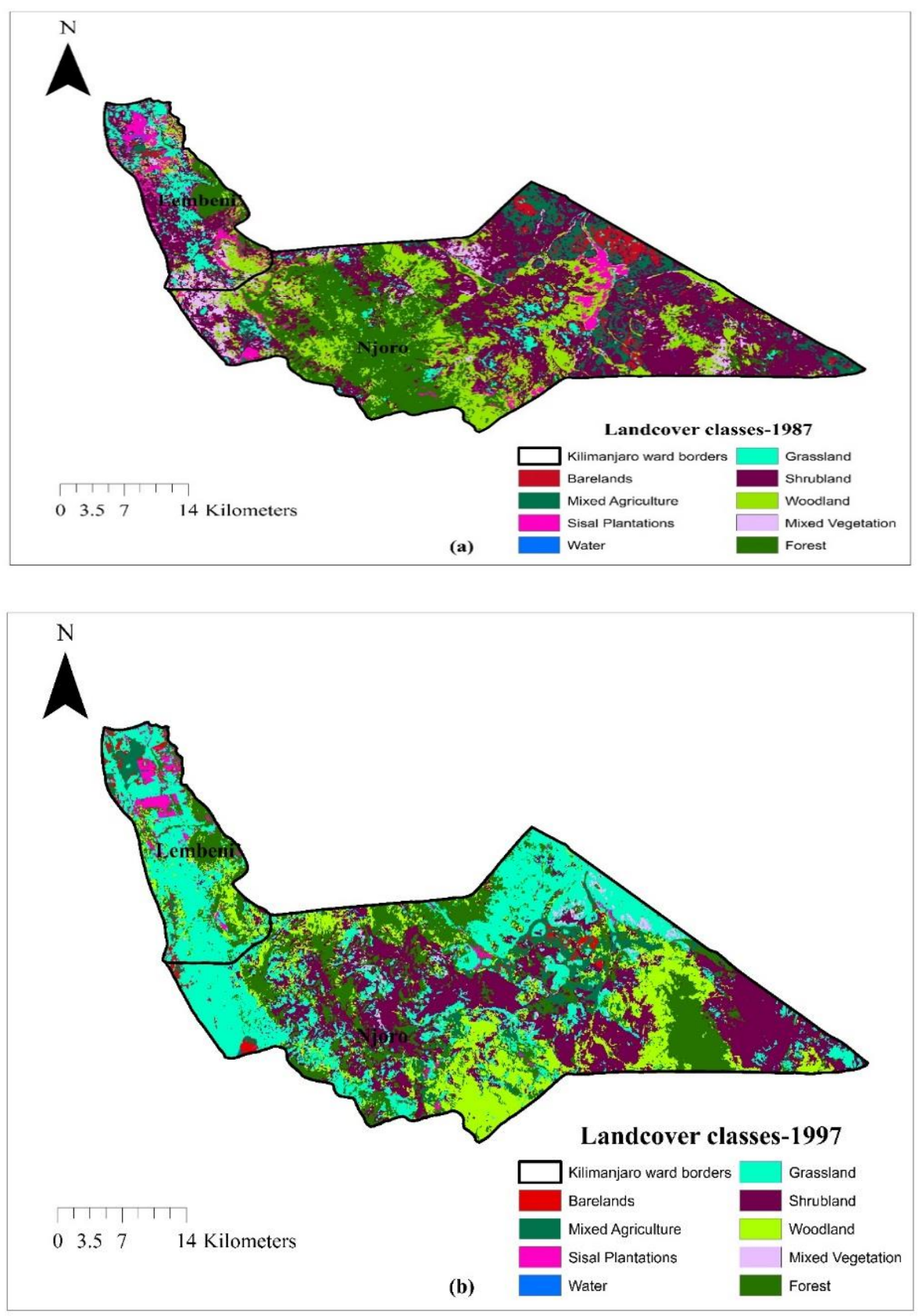

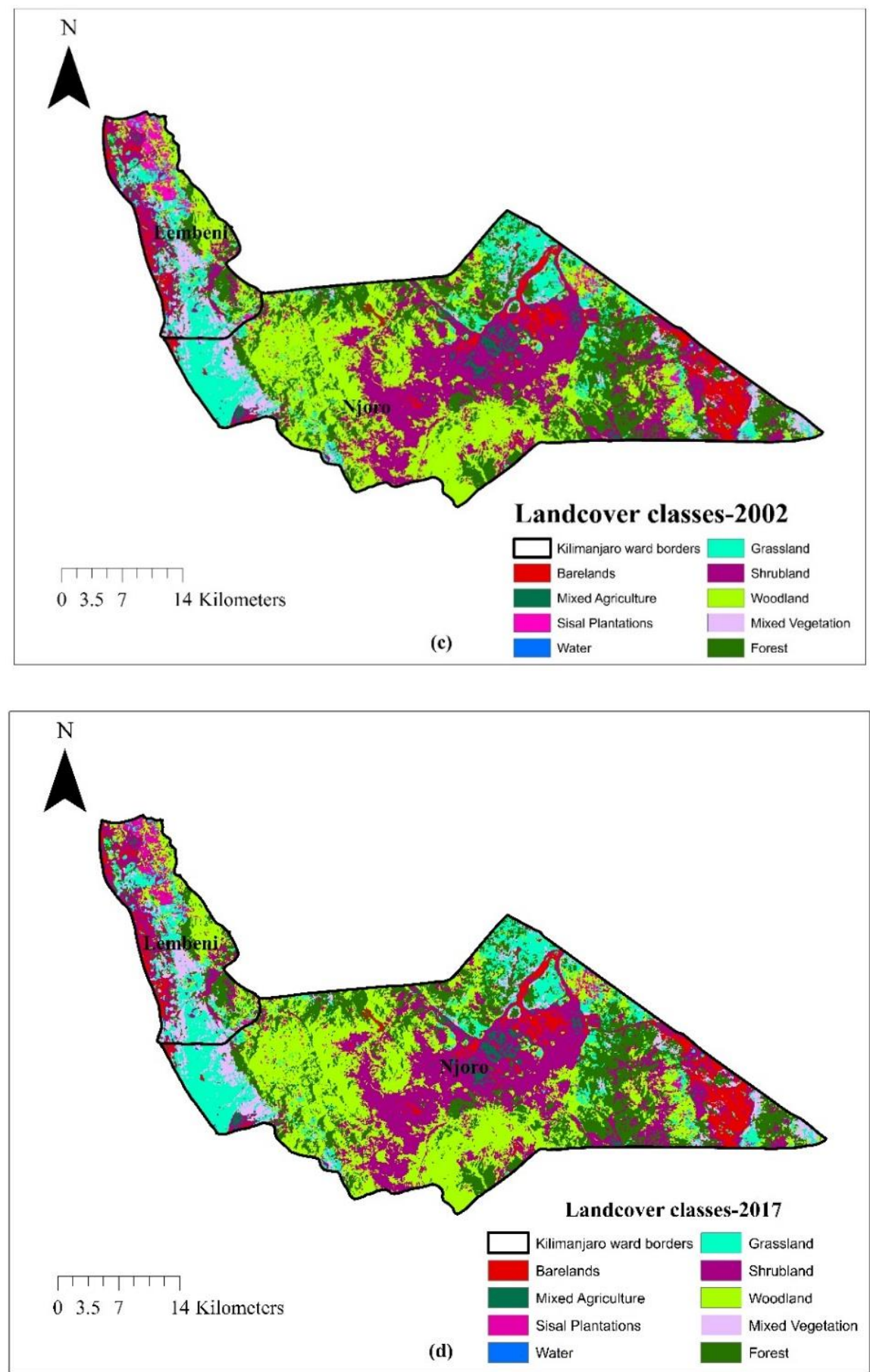

Figure 6: Image classification for (a) 1987 (b) 1997 (c) 2002 and (d) 2017 land covers classes in Mwanga district (Kilimanjaro). 


\section{Discussion \\ Analysis of existing energy sources}

This study identified several fuels such as dry cow dung cake, firewood, charcoal, biogas and LPG that are used in cooking. These findings are similar to those presented by Sawe (2004). Miya et al. (2012) reported firewood and charcoal as the frequently used fuels in Tanzania. In this study, the mostly used fuels identified include firewood (used by $62.5 \%$ and $77.5 \%$ (Figure 4 ) of all households surveyed in Meru and Mwanga, respectively), charcoal (used by $2.5 \%$ and $20 \%$ (Figure 4 ) of the respondents in Meru and Mwanga, respectively) and dry cow dung cake (used by $41 \%$ of the respondents in Meru). Firewood and charcoal constitute the major cooking fuels in most developing countries (Trossero 2002). This was reflected also in the present study; however, in some of the surveyed households, all of the identified fuels such as firewood, charcoal, cow dung cake and LPG were used in a mixed way.

The dependency on wood fuel as source of energy in the study areas is overwhelming. Experimental evidence suggests that there are a number of factors which influence this situation (Luoga et al. 2000). The main factors are unavailability of alternative sources of energy and increasing prices of the available non-wood fuels (Sawe 2004). The findings from this study suggest that, while efforts to adopt other sources of fuels alternative to wood fuel in the study areas are highly recommended, renewable and less costly sources of fuel such as biogas should be adopted and used.

Energy demands, consumption and the effect of wood fuel use on forest cover

Official data on wood fuel consumption are often focused on industrial demands and neglect domestic consumption (Specht et al. 2015). An alternative for assessing domestic demands is to indirectly estimate wood fuel consumption through its relationships with socioeconomic variables that are authoritatively available through periodic population censuses (Arnold and Persson 2003). This allows reliable estimations that, although rough, are useful as an initial approach and have potential for practical applications (Salim and Ullsten 1999).

The survey conducted to 207 and 100 households of Meru and Mwanga Districts recognized 200 and 82 households, respectively depending on firewood as among their cooking fuels. The 2012 census conducted in Lembeni, Njoro, Mgagao, Ngarenanyuki and Oldonyosambu wards of Mwanga and Meru Districts reported a population of 31623 people at the average family size of 4.8 which is approximately 6588 households (NBS 2012). With respect to the census total population, about 5102 households equivalent to $96.6 \%$ in Meru and 1048 households equivalent to $94.6 \%$ in Mwanga depend on firewood. About $1400 \mathrm{~kg}$ of cow dung cake (in Meru), 2093 and $4196 \mathrm{~kg}$ of firewood, 308 and $416 \mathrm{~kg}$ of charcoal for 100 and 207 households surveyed in Mwanga and Meru, respectively were spent per day.

The findings on total consumption of energy revealed the extent to which rural populations depend on wood fuel and highlight its socioeconomic drivers. The dependence on wood fuel has a great meaning and implications to the environment and forest cover changes over time (Arnold and Persson 2003).

The consumption of firewood and charcoal per person per year is estimated to be very high and in satisfying this, great pressure on forest cover is generated (Foley 1985, Miya et al. 2012). Results obtained from this study suggest that wood fuel harvesting should not be ignored as an important source of forest degradation. This is similar to what was suggested by Bensel (2008) on the effects of wood fuel uses in forest degradation. To semiarid areas in the northern parts of Tanzania, a considerable portion of the rural population still rely on wood fuel for meeting their basic cooking needs (Kileo and Akyoo 2014). This allows a consumption of up to 101953 tons of tree biomass per year. 
In order to produce one ton of charcoal, about 10 tons of wood are required (Kilahama 2008). In Africa, 1 ha may contain up to 109 tons of wood (Engel and Frey 1996). With this comparison, if more than 101953 tons of wood are used annually, then 935 ha/year of forest mighty be cleared for wood.

Statistical data from the extracted and classified images shows the decrease to some of the forested areas. Charcoal making, logging, shifting agriculture, pole cutting, expansion of commercial farms and wood fuel uses are the major contributing factors for forest degradation in several areas (Arnold and Persson 2003). These factors are rarely or completely not practiced in the study areas since the communities that live into these areas engage themselves on pastoralism and seldom in agricultural activities. Therefore, these factors are not counted on deforestation process. Firewood and charcoal are the most frequently used sources of energy in these areas. These sources are obtained from fresh trees and some from dry branches (as reported in the conducted survey). Therefore, it is likely that deforestation processes existing in these areas are due to the serious dependence on wood fuel use, clearing of trees for fencing and settlement expansion.

Knowing the factors that accelerate the deforestation processes in semi-arid areas of Mwanga and Meru, deforestation rate can be calculated. This is done by comparing the amount of wood that is consumed in cooking and the amount of wood that one hectare contains. If one hectare is covered with 109 tons of wood (Engel and Frey 1996), then 101953 tons of wood and charcoal that are used in Mwanga (Lembeni, Njoro and Mgagao) and Meru (Ngarenanyuki and Oldonyosambu wards) per year represent 935 ha of forest that are cleared per year. With these estimations, if 935 ha are cleared per year in Meru and Mwanga Districts, then at the range of 5, 10 and 15 years, the cleared forest would be 4677 , 9353 and 14030 ha, respectively making a total loss of 28060 ha within a period of 30 years.
Total losses of 744 and 183 ha within a period of 30 years since 1987-2017 for Mwanga and Meru, respectively were depicted. Calculation obtained from wood coverage of one hectare (Engel and Frey 1996) showed the loss of 28060 ha due to wood fuel usage within a period of 30 years. However, from the extracted satellite images, only 927 ha were lost within this period. Comparing these values, forest losses obtained due to wood fuel uses were higher than that obtained from satellite images.

\section{Impacts of shifting from wood fuel to biogas use in cooking}

The impacts of shifting from wood fuel use to biogas have been reflected to areas of Mwanga District. The classified images for Mwanga showed that since 2002 to 2017, forested areas increased from 17939 to 30960 ha, respectively. The use of biogas in Tanzania was reported to commence since the 1990s (Rupf et al. 2015); however, biogas use in northern parts of Tanzania gained its popularity in the year 2008 ( $\mathrm{Ng}$ 'wandu et al. 2009). Though, the biogas in these areas was reported to be produced in little amounts (Kileo and Akyoo 2014), its positive effects in forest cover changes have been revealed.

In semi-arid areas of Meru, the forest cover is continually decreasing (Table 1), biogas is completely not used in these areas and hence the communities go on relying on wood fuel as their main energy sources.

Deublein and Steinhauser (2011) reported that, $0.26 \mathrm{~m}^{3}$ of biogas is estimated to be used up by one person per day in cooking. For the household owning a digester sized $9 \mathrm{~m}^{3}$ which is fed with $80: 20 \mathrm{~kg}$ of cow dung/water per day has an ability of producing $12564 \mathrm{~L}$ of biogas per month that can save an average of 2.4 people within 30 days (Deublein and Steinhauser 2011).

The conducted survey in Lembeni, Njoro, Mgagao, Ngarenanyuki and Oldonyosambu identified that 283 tons of wood were consumed by 31623 people per day, equivalent to $9 \mathrm{~kg}$ per person. With this population of 
Mahushi et al. - Impacts of wood fuel uses on forest cover ...

31623 people (equivalent to 4.8 people per household), if the surveyed community (with 6559 households) opt to shift from using wood fuel to biogas, about 15812 people will be excluded from using wood fuel. Again, if $9 \mathrm{~kg}$ of wood are consumed by one person in cooking per day then the total number of 15812 people will save about 142 tons per day equivalent to 51003 tons per year. From the 51003 tons of wood saved per year if households in the surveyed areas were to shift from wood fuel use to biogas, 468 ha of forests that were to be cleared for wood fuel will be saved per year.

\section{Conclusion}

Determination of the energy sources and pinpointing the impacts of wood fuel use to forest cover was carried out. The identified energy sources included cow dung cake, firewood, charcoal, biogas, and LPG. The demands for the mentioned energy sources excluding biogas amounted to 1400, 6289, 724 and $21 \mathrm{~kg}$ per day, respectively. The decrease in forest cover for the selected areas was 927 ha for the past 30 years. Pastoralists are sensitized to shift from using wood fuel to biogas. Due to this, it is anticipated that forest cover will increase and thus upsurge the capacity to fix carbon and hence mitigate climate changes.

\section{Competing interest}

The authors declare that there are no competing interests regarding this paper.

\section{Funding acknowledgement}

The authors would like to thank DAAD and ECOBOMA project for providing financial support for accomplishment of this work.

\section{References}

Arnold M and Persson R 2003 Reassessing the fuelwood situation in developing countries. Int. For. Rev. 5(4): 379-383.

Bensel T 2008 Fuelwood, deforestation, and land degradation: 10 years of evidence from
Cebu Province, the Philippines. Land Degrad. Dev. 19(6): 587-605.

Chiesa F, Dere M, Saltarelli E and Sandbank H 2009 UN-REDD in Tanzania. Project on Reducing Emissions from Deforestation and Forest Degradation in Developing Countries. v1. 1.

Congalton RG 1991 A review of assessing the accuracy of classifications of remotely sensed data. Remote Sens. Environ. 37(1): $35-46$.

Congedo L 2013 Semi-automatic classification plugin for QGIS. Sapienza University 1-25.

Dell RB, Holleran S and Ramakrishnan R 2002 Sample size determination. ILAR J. 43(4): 207-213.

Deublein D and Steinhauser A 2011 Biogas from waste and renewable resources: an Introduction. John Wiley \& Sons.

Engel T and Frey W 1996 Fuel resources for copper smelting in antiquity in selected woodlands in the Edom highlands to the Wadi Arabah/Jordan. Flora 191(1): 29-39.

Foody GM 2002 Status of land cover classification accuracy assessment. Remote Sens. Environ. 80(1): 185-201.

Foley G1985 Woodfuel, deforestation and tree growing in the developing world. Energy Policy 13(2): 190-192.

Kilahama F 2008 Impact of increased charcoal consumption to forests and woodlands in Tanzania. For. Ecol. Manag. 308: 45-55.

Kileo JO and Akyoo AM 2014 Technology transfer and farm-based renewable energy sources. The potential of biogas technology for rural development in Tanzania Vol. 2 NAF International Working Paper Series. Working Paper No. 14.

Lillesand T, Kiefer RW and Chipman J 2014 Remote sensing and image interpretation. John Wiley and Sons.

Luoga EJ, Witkowski ETF and Balkwill K 2000 Economics of charcoal production in Miombo woodlands of eastern Tanzania: some hidden costs associated with commercialization of the resources. Ecol. Econ. 35(2): 243-257. 
Mengistu DA and Salami AT 2007 Application of remote sensing and GIS inland use/land cover mapping and change detection in a part of south western Nigeria. Afr. J. Environ. Sci. Technol. 1(5): 99-109.

Miya M, Ball SMJ and Nelson FD 2012 Drivers of deforestation and forest degradation in Kilwa District. Mpingo Conservation and Development Initiative. Kilwa, Tanzania 34.

Ministry of Natural Resources and Tourism 2014 The forestry and beekeeping sub sector: Achievements, challenges and priorities. Dar es Salaam.

Mwampamba TH, Ghilardi A, Sander K and Chaix KJ 2013 Dispelling common misconceptions to improve attitudes and policy outlook on charcoal in developing countries. Energ. Sust. Dev. 17: 75-85.

NBS 2012 Population and housing census: population distribution by administrative areas. Ministry of Finance, Dar es Salaam, Tanzania.

Ng'wandu E, Shila L and ter Heegde FEW 2009 Programme implementation Document. Tanzania Domestic Biogas Programme.

http://www.bibalex.org/Search4Dev/files/3 38189/171748.pdf.

Rudel TK, Flesher K, Bates D, Baptista S and Holmgren P 2000 Tropical deforestation Literature: geographical and historical patterns. Unasylva-FAO 11-18.

Rupf GV, Bahri PA, de Boer K, and McHenry MP 2015 Barriers and opportunities of biogas dissemination in Sub-Saharan Africa and lessons learned from Rwanda, Tanzania, China, India, and Nepal. Renew. Sust. Energ. Rev. 52: 468-476.

Rutherford G, Guisan A and Zimmermann N 2007 Evaluating sampling strategies and logistic regression methods for modelling complex land cover changes. J. Appl. Ecol. 44(2): 414-424.

Salim E and Ullsten O 1999 Our forests, our future. Cambridge University Press.

Sawe E 2004 An overview of charcoal industry in Tanzania-issues and challenges; prepared For the national $\mathrm{R}$ and $\mathrm{D}$ committee on industry and energy. Tanzania Traditional Energy Development and Environment Organization (TaTEDO), Dar es Salaam.

Specht MJ, Pinto SRR, Albuquerque UP, Tabarelli M and Melo FP 2015 Burning Biodiversity: Fuelwood harvesting causes forest degradation in human-dominated tropical Landscapes. Glob. Ecol. Conserv. 3: 200-209.

Sunderlin WD, Angelsen A, Belcher B, Burgers P, Nasi R, Santoso L and Wunder S 2005 Livelihoods, forests, and conservation in developing countries: an overview. World Dev. 33(9): 1383-1402.

Trossero MA 2002 Wood energy: the way ahead. Unasylva 53(4): 3-12.

Zhan X, Sohlberg RA, Townshend JRG, DiMiceli C, Carroll ML, Eastman JC, Hansen MC and DeFries RS 2002 Detection of land cover changes using MODIS 250 m data. Remote Sens. Environ. 83(1): 336-350. 